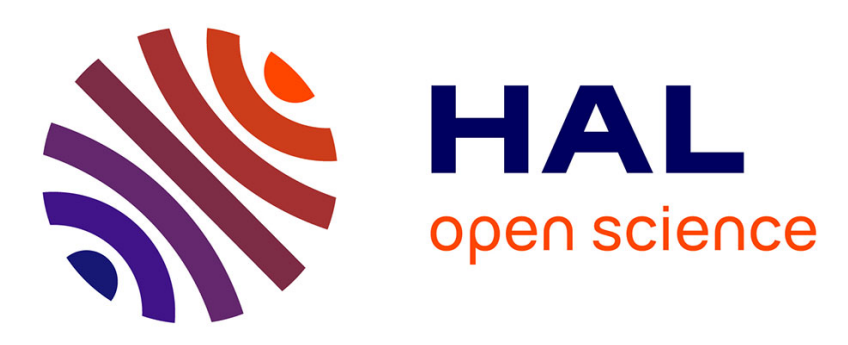

\title{
Neural harmonic detection approaches for FPGA area efficient implementation
}

S.R.N. Dzondé, C.-H. Kom, H. Berviller, J.-P. Blondé, D. Flieller, M. Kom, F. Braun

\section{- To cite this version:}

S.R.N. Dzondé, C.-H. Kom, H. Berviller, J.-P. Blondé, D. Flieller, et al.. Neural harmonic detection approaches for FPGA area efficient implementation. European Physical Journal: Applied Physics, 2011, 56 (3), pp.30901. 10.1051/epjap/2011100332 . hal-00751653

\section{HAL Id: hal-00751653 \\ https://hal.science/hal-00751653}

Submitted on 14 Nov 2012

HAL is a multi-disciplinary open access archive for the deposit and dissemination of scientific research documents, whether they are published or not. The documents may come from teaching and research institutions in France or abroad, or from public or private research centers.
L'archive ouverte pluridisciplinaire HAL, est destinée au dépôt et à la diffusion de documents scientifiques de niveau recherche, publiés ou non, émanant des établissements d'enseignement et de recherche français ou étrangers, des laboratoires publics ou privés. 


\title{
Neural Harmonic Detection approaches for FPGA Area efficient Implementation
}

\author{
S. R. N. Dzondé ${ }^{1,2}$, C-H. Kom ${ }^{2}$, H. Berviller ${ }^{1}$, J-P. Blondé ${ }^{1}$, D. Flieller ${ }^{3}$, M. Kom ${ }^{2}$, and F. Braun ${ }^{1}$ \\ ${ }^{1}$ Institut d'Electronique du Solide et des Systèmes (InESS), Université De Strasbourg /CNRS - UMR 7163,23 rue du Lœs, \\ 67037 Strasbourg, France \\ Tél. : +33 / (0) - 388106651 - Fax : +33 / (0) - 388106548 \\ Email : serge.dzonde@iness.c-strasbourg.Fr - Url: http://www-iness.c-strasbourg.Fr
}

${ }^{2}$ Laboratoire d'Electronique, Electrotechnique, Automatique Et Télédétection (LEEAT), University de Douala, B.P 8698 Douala, Cameroun

${ }^{3}$ Institut National Supérieur des Sciences Appliquées de Strasbourg, Laboratoire GREEN (UMR 7037, CNRS) Antenne de Strasbourg, 24 Bd de la Victoire, 67084 Strasbourg Cedex, France

\begin{abstract}
This paper deals with new neural networks based harmonics detection approaches to minimize hardware resources needed for FPGA implementation. A simple type of neural networks called Adaline is used to build an intelligent Active Power Filter control unit for harmonics current elimination and reactive power compensation. For this purpose, two different approaches called Improved Three-Monophase (ITM) and Two-Phase Flow (TPF) methods are proposed. The ITM method corresponds to a simplified structure of the three-Monophase method whereas the TPF method derives from the Synchronous Reference Frame method. Indeed, for both proposed methods, only $50 \%$ of Adalines with regard to the original methods is used. The corresponding designs were implemented on a FPGA Stratix II platform through Altera Dsp Builder ${ }^{\circledR}$ synthesis tool. After analyzing those two methods with respect to performance and size criteria, a comparative study with the popular $p$ - $q$ and also the direct method is reported. From there, one can notice that the $p-q$ is still the most powerful method for three-phase compensation but the TPF method is the fastest and the most compact in terms of size. An experimental result is shown to validate the feasibility of FPGA implementation of ANN-based harmonics extraction algorithms.
\end{abstract}

Keywords. «Neural Networks», «Active Filter», «Harmonics », «Estimation technique», «resource consumption»

\section{Introduction}

I $\mathrm{n}$ the attempt to minimize current harmonics disturbances created by non-linear loads (rectifiers, inverters, AC regulators, etc.), the Active Power Filter (APF) is one of the most advanced solutions. It is therefore used in a distribution power system to avoid serious inherent problems such as transformer overheating, machine vibration, motor failures and higher line losses, etc. In presence of nonlinear loads, harmonics are added on the source current, so creating a disturbed current. The injection of compensation currents in the electrical power supply by means of an APF allows sinusoidal current shape recovery.

An Active Power Line Conditioner can be used for general compensation in unbalanced/distorted electrical power systems [1]. In particular, an APF is used for current harmonics detection and reactive power compensation. As shown in fig. 1, its control unit is split into two main blocks: the first one is for current harmonics identification in order to produce the required reference currents for the control algorithms, while the second one carries the control method for injecting opposite phases of these currents into the power grid.

The technique used to obtain the reference currents has a decisive influence on the APF efficiency and performance. An evaluation of the techniques traditionally used for this purpose, either in the time- or frequency-domain is given in [2]. In frequency-domain, most of the algorithms are based on the Fourier theory. A drawback of this technique is the impossibility of obtaining precise results in transient state. There is a great diversity among the techniques operating in the time-domain, including the least square error technique and Kalman filtering [3-4]. Beyond their simplicity they cannot easily take noises and errors into account, and they need incompressible time-delay for convergence. The most powerful technique is with no doubt the Instantaneous Power Theory (IPT) [2],[5- 7], proposed by H. Akagi. However, the original $p-q$ formulation derived from this theory is not available for single phase compensation.

In recent years, artificial intelligence techniques have been applied to control APFs. A review of artificial intelligence techniques such as neural networks or fuzzy logic used for control issue in power systems is proposed in [8]. Indeed, the work in [9] proposes a multi-layer neural network-based fast power system harmonic detection, which requires only one half of the distorted wave to perform efficiently even in noisy conditions in the tolerance of 5\%. It is also reported in [10], that synchronous frame adaptive linear neural networks used to control a T-type APF achieves good performance with better dynamic response and lower Total Harmonic Distortions (THD) in source-side currents. For its part, Ould Abdeslam et al. went further in the work discussed in [7] while proposing a unified 
neural approach of the entire adaptive harmonics compensation system. The approach generalized the use of a single and simplified type of neural network called Adaline Neural Network (ANN) [11]. The simple and flexible structure obtained, also leads to optimal hardware resources consumption during digital implementation.

On this subject, due to the parallelism and pipelining technologies, it is known that application specific hardware implementation can offer much greater speed than software implementation using Digital Signal Processors (DSP) or microprocessors. There are essentially two types of technologies available for hardware design: full custom hardware design, known as Application Specific Integrated Circuit (ASIC) and semi custom programmable devices such as FieldProgrammable Gate-Array (FPGA). While it can offer the highest performance, the ASIC cannot be reconfigured. Implementing complex algorithms on reprogrammable devices minimizes the time-to-market cost, enables easy and fast circuit modification and rapid prototyping through Hardware Description Language (HDL) [12-13]. According to what is shown in [14], FPGA seems to be an excellent choice for artificial neural networks implementation. Indeed, it is also reported in [15] an implementation on FPGA Stratix EP1S80 of ANNs-based harmonics identification algorithms by means of the direct method with quite good results.

In the next section of this paper, two proposed neural harmonics detection methods are described, i.e. an improved version of the three-monophase method [7] and another one called Two-Phase Flow introduced in [16]. In section III, those two approaches are compared to three other methods according to their modeling structure, their harmonic compensation performance and hardware resource consumption during implementation on a medium size FPGA target.

\section{New Architectures for Neural Harmonic Detection Methods}

Originally, formal neural networks were a mathematical attempt at human brain modeling. Nowadays, several applications of ANNs can be found in many fields [17-18]. As reported in [15], the general network topology of an Adaline, is as shown in fig. 2. The objective of an Adaline is to approximate a desired signal $y(t)$ to generate $y(t)_{e s t}$ by the linear relation (1) :

$$
y(t)_{e s t}=\mathbf{W}^{T}(t) \mathbf{X}(t)
$$

$\mathbf{X}(t)$ is the input vector and $\mathbf{W}^{T}(t)$ represents the weight vector updated during the learning process, such that the error $e$ between the desired function $y(t)$ and the ANN output $y(t)_{e s t}$ is minimal. The simplest form of the LMS learning rule which convergence has been proven in [17] is represented by equation (2).

$$
\mathbf{W}(t+1)=\mathbf{W}(t)+\frac{\mu e(t) \mathbf{X}(t)}{\mathbf{X}^{T}(t) \mathbf{X}(t)}
$$

For most applications, the learning rate $\mu$ can be empirically determined without prejudice to the scientific rigor of the work.

\subsection{ITM identification Method}

As presented in fig. 3, the three-monophase method works directly with the distorted current $i_{L}(t)$ and identifies fundamental component $i_{L f}(t)$, and thus the harmonics $i_{L h}(t)$ for each phase with two Adalines. We can see in [7], the detailed equations characterizing the Adalines. For the first one, multiplying the load current by $\sin \omega t$, we obtain the expression (3)

$$
\begin{aligned}
& i_{L}(t) \sin \omega t=\frac{1}{2}\left(I_{12}-I_{12} \cos 2 \omega t+I_{11} \sin 2 \omega t\right) \\
& +\frac{1}{2} \sum_{n=2 \ldots n}\left(I_{n 2} \cos (n-1) \omega t-I_{n 2} \cos (n+1) \omega t\right) \\
& +\frac{1}{2} \sum_{n=2 \ldots n}\left(I_{n 1} \sin (n+1) \omega t-I_{n 1} \sin (n-1) \omega t\right)
\end{aligned}
$$

where $I_{12}$ is the bias weight of the corresponding Adaline. For the other Adaline, issue from the multiplication of $i_{L}(t)$ and $\cos \omega t, I_{11}$ is the bias weight. By looking more closely at equation (3), it can be noticed that besides the weight $I_{12}, I_{11}$ can also be determined as the steady state weight corresponding to the input $1 / 2 \sin 2 \omega t$ of the same Adaline. Figure 4 illustrates the ITM principle.

\subsection{Two-Phase Flow Method}

The second proposed identification method, i.e. the Two-Phase Flow (TPF) works on the $D Q$-space according to the structure of fig.5. This neural approach relies on an original decomposition of the three-phase currents. These currents are successively converted into the $\alpha \beta$ - and $D Q$-spaces with respectively the Concordia and Park transforms. The $D Q$-space allows to decompose the currents in linear expressions and to separate the AC from the DC components.

\subsubsection{Principle}

Considering the simplified expression (4) of the polluted load three-phase currents, the first part represents the fundamental current and the second one the sum of harmonics. 


$$
\left[\begin{array}{c}
i_{L 1} \\
i_{L 2} \\
i_{L 3}
\end{array}\right]=I_{1}\left[\begin{array}{c}
\cos \left(\omega t-\alpha_{1}\right) \\
\cos \left(\omega t-\alpha_{1}-2 \pi / 3\right) \\
\cos \left(\omega t-\alpha_{1}+2 \pi / 3\right)
\end{array}\right]+\sum_{n=2 \ldots N} I_{n}\left[\begin{array}{c}
\cos \left(n \omega t-\alpha_{n}\right) \\
\cos \left(n \omega t-\alpha_{n}-2 \pi / 3\right) \\
\cos \left(n \omega t-\alpha_{n}+2 \pi / 3\right)
\end{array}\right]
$$

$I_{l}$ and $I_{n}$ are amplitudes of the load current fundamental and harmonic components. The expression (4) can also be written in the form (5),

$$
\left[\begin{array}{l}
{ }^{i_{L 1}} \\
i_{L 2} \\
i_{L 3}
\end{array}\right]=\mathbf{T}_{32} \mathbf{P}(\omega t)\left[\begin{array}{c}
i_{D} \\
i_{Q}
\end{array}\right]
$$

where $\mathbf{T}_{32}$ and $\mathbf{P}(\omega \mathrm{t})$ are respectively Concordia and Park transformation matrices to the $\alpha \beta$ - and $D Q$-spaces.

$\mathbf{P}(\omega t)=\left[\begin{array}{cc}\cos (\omega t) & -\sin (\omega t) \\ \sin (\omega t) & \cos (\omega t)\end{array}\right]$ and $\mathbf{T}_{32}=\left[\begin{array}{cc}1 & 0 \\ -1 / 2 & \sqrt{3} / 2 \\ -1 / 2 & -\sqrt{3} / 2\end{array}\right]$

The index terms designate the direct and quadrature coordinate frame $(D$ and $Q)$. The transformation consists first of all of writing the currents into the $\alpha \beta$ space with expression (6) and thereafter into the $D Q$ space with the relation (7).

$\left[\begin{array}{c}i_{\alpha} \\ i_{\beta}\end{array}\right]=\mathbf{T}_{32}^{T}\left[\begin{array}{c}i_{L 1} \\ i_{L 2} \\ i_{L 3}\end{array}\right]=\sqrt{\frac{3}{2}} I_{1}\left[\begin{array}{c}\cos \left(\omega t-\alpha_{1}\right) \\ \sin \left(\omega t-\alpha_{1}\right)\end{array}\right]+\sum_{n=2 . . N} \sqrt{\frac{3}{2}} I_{n}\left[\begin{array}{c}\cos \left(n \omega t-\alpha_{n}\right) \\ \sin \left(n \omega t-\alpha_{n}\right)\end{array}\right](6)$
$\left[\begin{array}{c}i_{D} \\ i_{Q}\end{array}\right]=\mathbf{P}(-\omega t)\left[\begin{array}{c}i_{\alpha} \\ i_{\beta}\end{array}\right]=\sqrt{\frac{3}{2}} I_{1}\left[\begin{array}{c}\cos \left(\alpha_{1}\right) \\ -\sin \left(\alpha_{1}\right)\end{array}\right]+\sum_{n=2 \ldots N} \sqrt{\frac{3}{2}} I_{n}\left[\begin{array}{c}\cos \left((n-1) \omega t-\alpha_{n}\right) \\ \sin \left((n-1) \omega t-\alpha_{n}\right)\end{array}\right](7)$

From (7) we can separate the DC component (8) which appears as fundamental currents into the $D Q$-space and the AC component of formula (9), representing harmonic currents into the same space. Thereafter, reference currents can be obtained by equation (15).

$$
\begin{gathered}
{\left[\begin{array}{l}
\bar{i} D \\
\bar{i} Q
\end{array}\right]=\sqrt{\frac{3}{2}} I_{1}\left[\begin{array}{c}
\cos \left(\alpha_{1}\right) \\
-\sin \left(\alpha_{1}\right)
\end{array}\right]} \\
{\left[\begin{array}{l}
\tilde{i} D \\
\tilde{i} \\
i Q
\end{array}\right]=\sum_{n=2 \ldots N} \sqrt{\frac{3}{2}} I_{n}\left[\begin{array}{l}
\cos \left((n-1) \omega t-\alpha_{n}\right) \\
\sin \left((n-1) \omega t-\alpha_{n}\right)
\end{array}\right]} \\
{\left[\begin{array}{l}
i_{r e f 1} \\
i_{r e f 2} \\
i_{r e f 3}
\end{array}\right]=\mathbf{T}_{32} \mathbf{P}(\omega t)\left[\begin{array}{l}
\sim \\
i D \\
\tilde{r} \\
i Q
\end{array}\right]}
\end{gathered}
$$

An Adaline-based architecture is proposed and adopted to learn the linear expressions of the currents. By iteratively adapting their weights online, the Adaline is able to find out those DC and then AC components.

\subsubsection{Extraction of harmonic currents with Adaline (DQ-space)}

From the relation (7) we can obtain the current $i_{D}$ with expression (11) :

$$
\begin{aligned}
& i_{D}=\sqrt{\frac{3}{2}} I_{1} \cos \left(\alpha_{1}\right)+\sum_{n=2 \ldots N} \sqrt{\frac{3}{2}} I_{n} \cos \left((n-1) \omega t-\alpha_{n}\right) \\
& =\sqrt{\frac{3}{2}} I_{1} \cos \left(\alpha_{1}\right)+\sum_{n=2 \ldots N} \sqrt{\frac{3}{2}} I_{n}\left[\cos ((n-1) \omega t) \cos \left(\alpha_{n}\right)\right) \\
& \left.\left.+\sin ((n-1) \omega t) \sin \left(\alpha_{n}\right)\right)\right]
\end{aligned}
$$

The current $i_{D}$ expression (11) can be written in vectorial notation by the relation (12):

$$
i_{D}=\mathbf{W}_{D}^{T} \mathbf{X}_{D}^{(t)}
$$

with $\mathbf{W}_{\mathrm{D}}^{\mathrm{T}}=\left[\begin{array}{lll}\sqrt{\frac{3}{2}} I_{1} \cos \left(\alpha_{1}\right) \quad \sqrt{\frac{3}{2}} I_{5} \cos \left(\alpha_{5}\right) & \cdots \sqrt{\frac{3}{2}} I_{n} \cos \left(\alpha_{\mathrm{n}}\right)\end{array}\right]$ and $\mathbf{X}_{D^{(t)}}=\left[\begin{array}{llll}1 & \cos 4 \omega t & \ldots & \sin (n-1) \omega t\end{array}\right]$

The vector $\mathbf{X}_{D}(t)$ elements are Adaline inputs whereas those of $\mathbf{W}_{\mathrm{D}}^{\mathrm{T}}$ are Adaline weights. Particularly, the weight $W_{0}(\mathrm{k})$ estimates the DC component $\bar{l}_{D}$ along the $\mathrm{D}$ axis. From its value $\sqrt{\frac{3}{2}} I_{1} \cos \left(\alpha_{1}\right)$, we can easily obtain along the $\mathrm{Q}$ axis the estimated value $-\sqrt{\frac{3}{2}} I_{1} \sin \left(\alpha_{1}\right)$ of the DC component $\bar{\imath}_{Q}$ by the equation (13),

$$
\bar{i} Q=-\sqrt{\frac{3}{2}} I_{1} \sin \left[\operatorname{acos}\left(\sqrt{\frac{2}{3}} \frac{\bar{i} D}{I_{1}}\right)\right]
$$

The AC components $\tilde{i}_{D}$ and $\tilde{i}_{Q}$ representing harmonic currents respectively along $\mathrm{D}$ and $\mathrm{Q}$ axis will be calculated from relations (14-15):

$$
\begin{aligned}
& \tilde{i}_{D}=i_{D}-\bar{i}_{D} \\
& \tilde{i}_{Q}=i_{Q}-\bar{i}_{Q}
\end{aligned}
$$

By applying $\mathbf{T}_{32}$ and $\mathbf{P}(\omega \mathrm{t})$ to those currents, we can finally obtain the reference currents $i_{r e f 1}, i_{r e f 2}$ and $i_{\text {ref } 3}$ in the three-phases system. Figure 5 reveals the proposed ANN-based scheme which makes it possible to obtain all the reference currents with only one Adaline. 


\section{Results and Discussion}

In order to maintain the power quality, European standards were created to set levels for harmonic currents injected by loads back on to the network [19]. The THD has been defined as a measurement of harmonic content in a signal. In our work, we proposed to evaluate two identification methods by using a typical case which is representative of the power quality environment of our experimental APF test bench. The power system of three-phase three-wire type is modeled with MatLab/simulink/SimPowerSystems block sets. It is characterized by $50 \mathrm{~Hz}$ frequency and $81.65 \mathrm{~V}$ source voltage phase to phase amplitude. The non-linear load consists of a three-phase rectifier connected to a passive $\mathrm{R}-\mathrm{L}$ branch $(\mathrm{R}=20 \Omega$ and $\mathrm{L}=6,25 \mathrm{mH})$. The resulting load current is distorted by two dominant harmonics $\left(5^{\text {th }}\right.$ and $7^{\text {th }}$ order) and is characterized by a THD of $28 \%$.

Assuming that an accurate and fast detection of the utility voltage phase angle is essential to ensure the correct generation of reference signals, we use for this purpose a neural Phase-Lock Looped (PLL) proposed in [20]. We first carried out the simulation of the harmonics identification algorithms independently with a sampling period of $10 \mu \mathrm{s}$.

\subsection{Harmonics Detection methods simulation}

In case of balanced three-phase source voltage, the simulations waveforms are shown in fig. 6 . After harmonics separation, from the distorted load current of fig. 6.a), a fundamental component is obtained by means of the TPF method (fig. 6.b) and the ITM method (fig. 6.c). On the other hand, a sudden variation of the load at $0.08 \mathrm{~s}$ leads to the results of fig. 7 . It is there presented from the load current of fig. 7.a), the extracted fundamental component with the TPF method fig.7.b) and the ITM method (fig. 7.c). In addition, table I shows the settling time and the fundamental component THD obtained for both methods in comparison to that of three other methods. We can then notice that the TPF method with a settling time of $20 \mathrm{~ms}$ is the most faster whereas the ITM method seems less powerful than the others for it has a settling time of $45 \mathrm{~ms}$ and a corresponding fundamental component THD of $1 \%$.

Furthermore, the TPF technique also shows the best filtering performance with the smallest THD value, i.e. $0.6 \%$ which is slightly equal to that of the $p-q$ method. We also noticed on table I that the training process of the ITM method is slightly slower than that of the original three-monophase method. As we can see in fig. 4 , it could be explained by the minor stability problem resulting from the fact that the weight $I_{11}$ is obtained from a sinusoidal input and therefore is not a bias weight as $I_{12}$.

\subsection{Simulation of the whole APF control unit}

To enlighten the identification methods performance in a whole harmonic filtering process by means of APF, we kept the same current control strategy based on the Bandless Hysteresis [21]. Besides, as the power circuit, we used a six-pulse inverter with a first order R-L filter.

From the same load current of fig. 6.a), we obtain the source currents after compensation presented in fig. 8 . With the same load variation resulting to the load current of fig 7.a), source currents after harmonics mitigation are shown in fig. 9 for respectively TPF (fig. 9.a) and ITM methods (fig. 9.b). A measurement is then made to obtain source currents THD after compensation. Those two neural methods are particularly compared to the popular $p-q$ method according to various criteria as shown in table II.

\subsection{Implementation process}

Control algorithms are developed on Altera Dsp Builder $^{\circledR}$ interface. The rapid prototyping target is a medium scale FPGA Stratix II, i.e EP2S180F1020, as shown on the experimental platform of fig. 10. The objective of reducing area consumption is also achieved by choosing the appropriate bus sizes throughout the model and applying modular design [12] without any redundant block. As shown in table III, the TPF method is the less consuming technique for harmonics extraction. It uses only $21.6 \%$ of FPGA calculation resources while the ITM technique uses $52 \%$, the neural $p-q$ formulation and the direct method $45.3 \%$ and $31.33 \%$ respectively. An attempt to implement the trimonophase method failed because the fitter required more logic array blocks, i.e. 12,278 than available on the FPGA target, i.e. 8,970. This can be explained by the important number of Adalines used for harmonics detection, i.e. sixth instead of three for the proposed ITM method. According to its structure, the Adaline appears as the most consuming part of the design. So, both proposed methods were especially focused on the reduction of Adalines blocks, to minimize FPGA resources. As the $p-q$ method, the TPF is only based on a single Adaline.

ITM and direct harmonic detection methods only work on a single phase. Consequently, three similar identification blocks are needed for three-phase extraction. On the other hand, the TPF method is different in the sense that it works directly on a threephase distorted current, as in the IPT theory, but with a transformation into the $D Q$-space.

From the above results, the TPF method seems better than the ITM method. Moreover, it has performances almost equivalent to that of $p-q$ technique in term of 
rapidity. We have to consider that the comparison is done in case of a balanced three-phase source voltage. For unbalanced conditions, the PLL used for phase detection in the TPF strategy should also be made up of a neural symmetrical component extraction block discussed in [20].

In spite of the fact that ANNs are not normally considered $100 \%$ reliable in their ability to interpolate, their reliability for the presented active filtering application is proven in simulations by the obtained settling times and THD values.

\subsection{Experimental setup}

The experimental prototype basically included a three-phase APF, a nonlinear load, a computer, and FPGA board associated with a low frequency analog inputs card.

The power stage consists of a Semikron SKM 50 GB 123D inverter with insulated-gate bipolar transistor (IGBT) modules. The split capacitor of the dc bus is $4400 \mu \mathrm{F}$ and R-L branches are applied to suppress the filter current ripple. Such a design can operate at a lineto-neutral voltage of $230 \mathrm{~V}$ rms and $10-\mathrm{kVA}$ power.

In this setup, the board including the FPGA EP2S180F1020 target is used for real-time calculation and control of the reference current, while generating the gating signals to drive the IGBTs. An auxiliary low frequency analog card is used for assuring acquisition and A/D conversion of the current and voltage signals for the FPGA, and also to amplify the gating signals from $0-3.3 \mathrm{~V}$ to $0-15 \mathrm{~V}$ for the needs of IGBTs.

The nonlinear load is made up of a diode rectifier and a R-L branch in the dc side. Due to real-time constraints, the switching frequency of the IGBT has been set to $12.5 \mathrm{kHz}$ which is adequate for this application.

The system parameters are summarized in Table IV. where $V s$ and is the line source voltage, $f$ is the system frequency, $V_{D C}$ is the voltage of the dc bus capacitor $C_{D C}, R_{f}$ and $L_{f}$ are respectively the filter resistance and inductance, $f_{s w}$ is the switching frequency, $R_{L}$ and $L_{L}$ are respectively the load resistance and inductance.

We only present experimental measurements of fig. 11 due to the fact that reference current waveforms extracted from the load current are quite similar for the different methods. Table $\mathrm{V}$ shows the THD of the source-side current after the APF compensation for an initial THD of $30 \%$. The best result is obtained for the ITM method with a THD of $4.2 \%$. All the THD values, especially the one for the TPF method can be reduced by choosing an APF output filter of third order to fit the source current inside the distortion bounds set at $5 \%$ by the standard. Again, an outstanding improvement in all harmonic components may clearly be seen, obtaining good sinusoidal source currents in phase with the fundamental component of the voltage signal, i.e. a unity power factor.

\section{Conclusions}

A hardware implementation of two adaptive harmonics identification techniques based on neural networks has been presented. Whatever the harmonic detection method used for the APF control unit, the compensated source current THD value well agrees with IEC standards. In addition to the APF performances, even the most consuming ITM method presents interesting perspectives in terms of FPGA material resources reduction by consuming less than $52 \%$ of FPGA calculation resources. This validates once more the feasibility for neural networks implementation. So, with careful design, mapping the algorithm with adequate system performance is reachable despite the lack of resources. Besides, with the smallest settling time, i.e. $20 \mathrm{~ms}$ and the smallest resource utilization ratio, i.e. $21.6 \%$ for three-phase compensation, the TPF method appears as one of the best harmonics identification method.

Although other methods for the control of active filters are widely known, the hardware implementation of the whole APF control unit with only neural networks is an interesting issue, meaning that ANNsbased techniques are of efficient application in power electronics. The use of FPGA target for such applications certainly improves the global performances due to its aptitudes for parallel processing.

\section{References}

[1]. J. R. Vasquez, P. Salmeron, J. Prieto, and F.J. Alcantara, in Proceedings of $14^{\text {th }}$ PSCC, Sevilla, 2002, s28, p.06

[2]. L. Asiminoaei, F. Blaabjerg, and S. Hansen, in Proceedings of APEC'05, Austin, Texas, 2005, p. 635

[3]. M. Su, D. Li, W. Yang, and H. Peng, in Proceedings of the ${ }^{\text {th }}$ China-Japan International Workshop on ITCA, Hunan, 2005, p. 99

[4]. V. Moreno, A. Pigazo, and R.I. Diego, in Proceedings of the $10^{\text {th }}$ International Conference on Harmonics and Quality of Power, 2002, 2, p. 490

[5]. H. Akagi, IEEE Trans. Ind. Appl., 32, 6 (1996)

[6]. R. S. Herrera, P. Salmerón, and H. Kim, IEEE Trans. Ind. Electron., 55, 1 (2008)

[7]. D. Ould Abdeslam, P. Wira., J. Mercklé, D. Flieller, and Y.A. Chapuis, IEEE Trans. on Industrial Electronics, 54, 1 (2007)

[8]. R. Bansal, T.Bhatti, and D. Kothari, International Journal of Power and Energy Systems, 23, 2 (2003)

[9]. H. C. Lin, IEEE Transactions on Industrial Electronics, 54, 1 (2008)

[10]. Y. Han, M. Khan, G. Yao, Li-D. Zhou, and C. Chen, Simulation Modelling Pratice and Theory, 16, (2007) 
[11]. B. Widrow, and E. Walach, ser. Information and System Science Series. Upper Saddle River, NJ, (Prentice Hall Press, 1996)

[12]. Z. Shu, Y.Guo, and J. Lian, IEEE Transactions on Industrial Electronics, 55, 4 (2008)

[13]. Y.A. Chapuis, J.P. Blondé, and F. Braun, in Proceedings of EPE-PEMC, Riga, 2004, vol. 1, p. 134

[14]. E. Won, Nuclear Instruments and Methods in Physics Research, 581, 816 (2007)

[15]. S. R. D. Naoussi, H. Berviller, J.-P Blondé, C. H. Kom, and F. Braun, in Proceedings of DASIP'08, Brussels, 2008, p. 270

[16]. S. R. D. Naoussi, H. Berviller, J-P. Blonde, F Braun, C H. Kom, and M. Kom, in Proceedings of the $13^{\text {th }}$ European Conference on Power Electronics and Applications (EPE'09), Barcelona, 2009, CDROM.

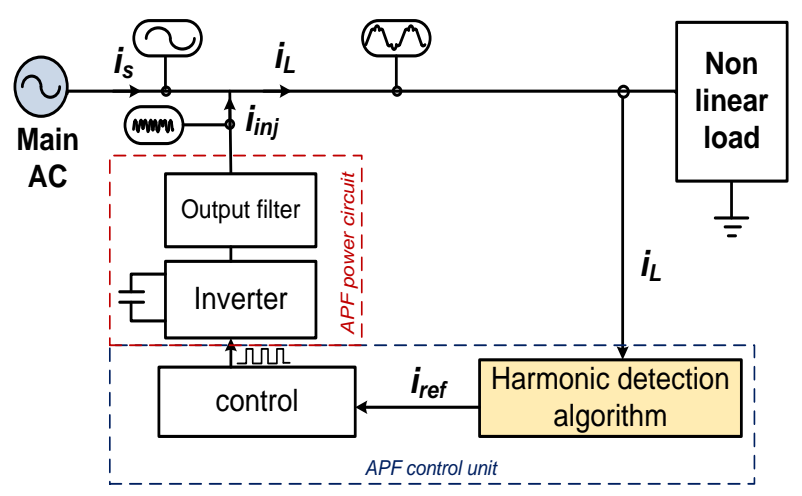

Fig. 1. A shunt APF in an electrical power system

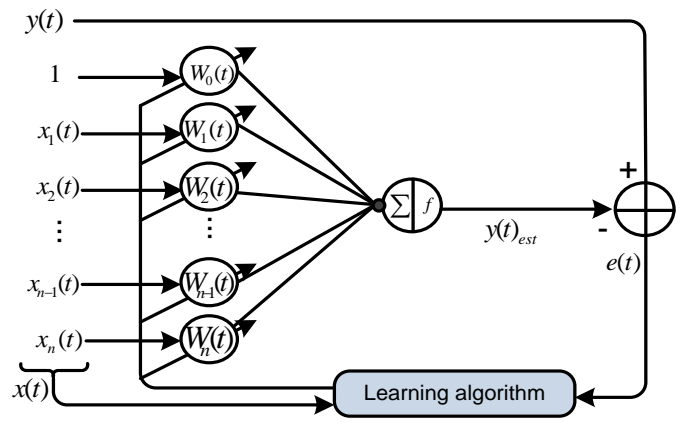

Fig. 2. Adaline topology

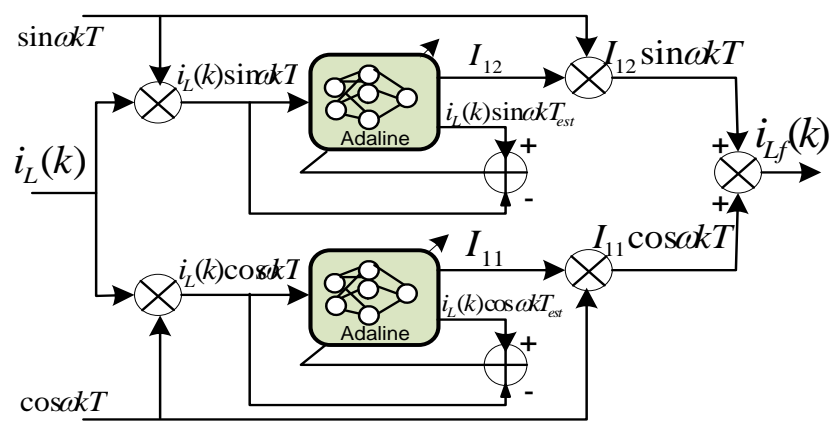

Fig. 3. Three-monophase design with two Adalines
[17]. Y. J. Chen and W. P. Du Plessis, in Proceedings of the $6^{\text {th }}$ IEEE Africon, 2002, 1, p. 337

[18]. S. S. Kim, and S. Jung, in Proceedings of IEEE ICRA'O4, New Orleans, 2004, 5, p. 4639

[19]. Electromagnetic Compatibility (EMC)_Part 3-2: Limits-Limits for Harmonic Current Emissions (Equipment Input Current $<=16$ A Per Phase), IEC 61000-3-2, 2005.

[20]. N. K. Nguyen, D. Flieller, P. Wira, and D. Ould Abdeslam, in Proceedings of 35th Annual Conference of the IEEE Industrial Electronics Society (IECONO9), Porto (2009), CD-ROM.

[21]. M. A. M. Radzi and N. A. Rahim, IEEE Transactions On Industrial Electronics, 56, 5 (2009)

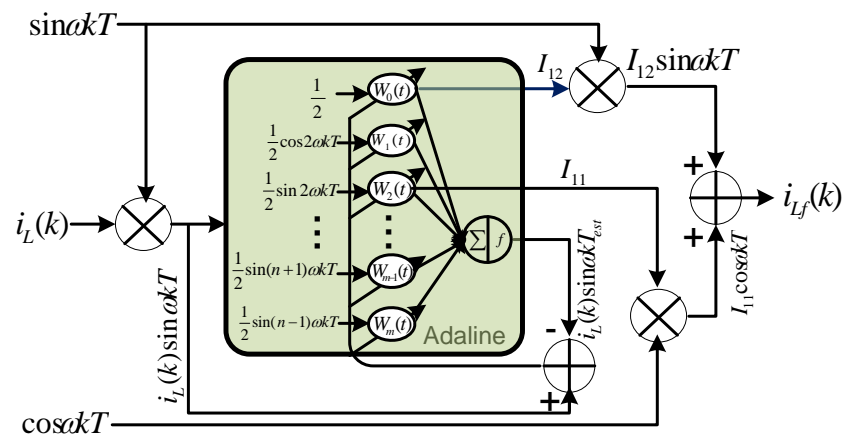

Fig. 4. ITM architecture with only one Adaline

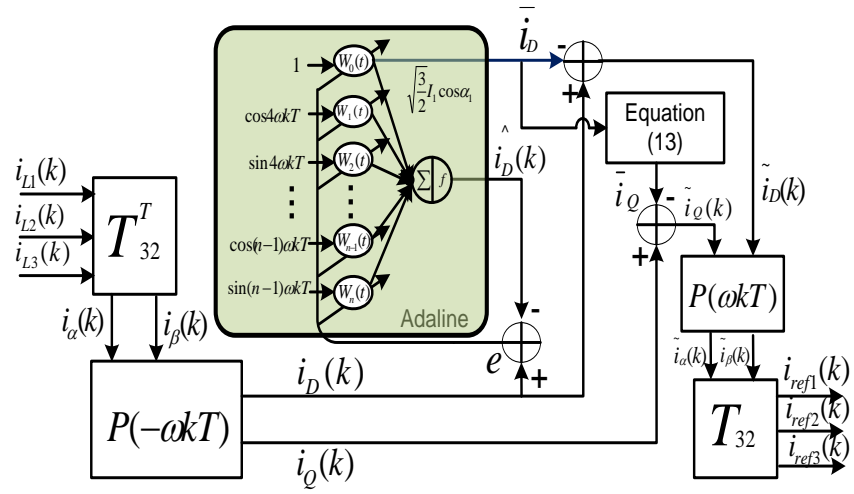

Fig. 5. Two-phase flow method with only one Adaline
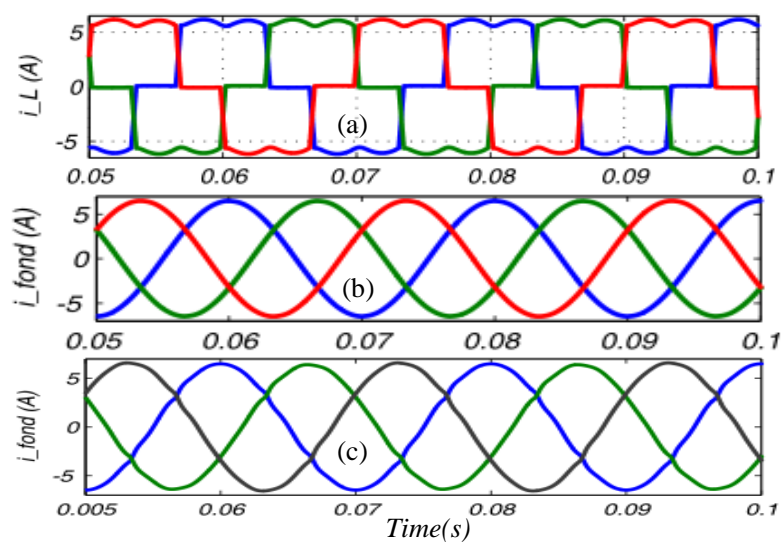

Fig. 6. Results under balanced load: Load current (a), Fundamental component extracted from the load current via the TPF (b) and the ITM (c) methods 


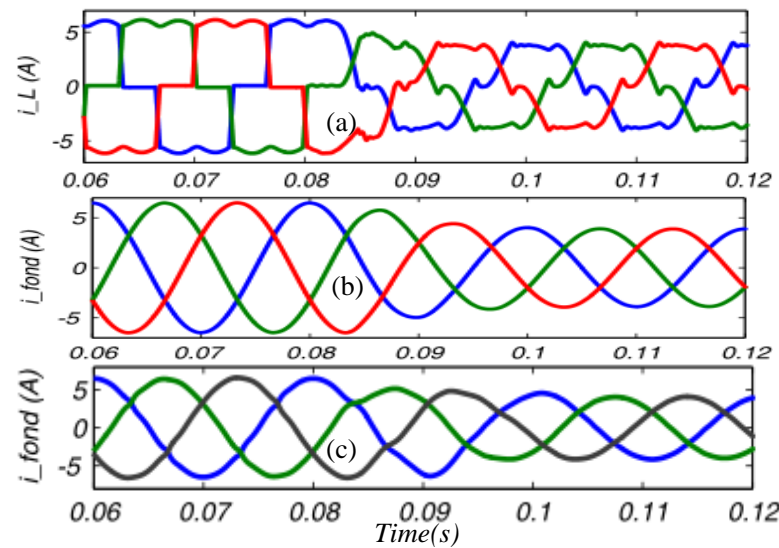

Fig. 7. Results under balanced load with a sudden change at 0.08s: Load current (a), Fundamental component extracted from the load current via the TPF (b) and the ITM (c) methods

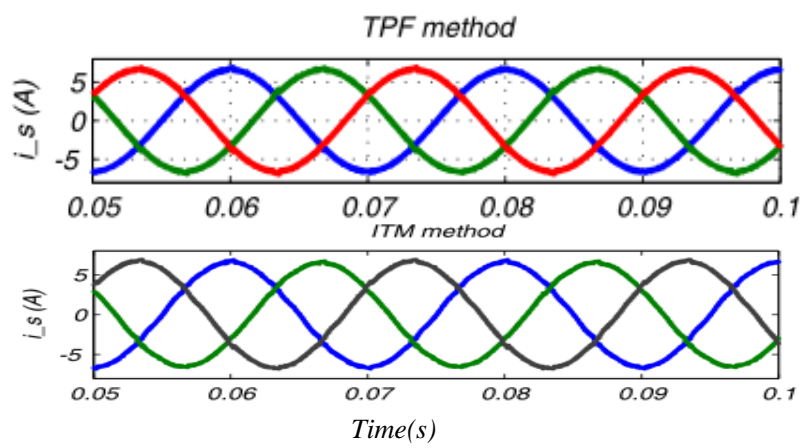

Fig. 8. Results under balanced load: Source currents after harmonics suppression via the detection methods

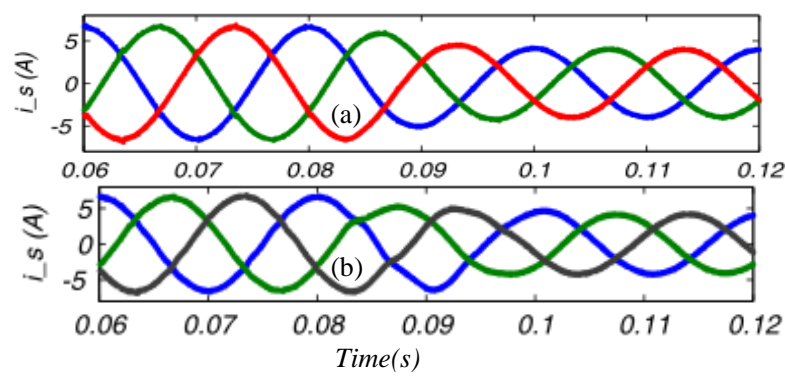

Fig. 9. Results under balanced load with a sudden change at $0.08 \mathrm{~s}$ : Source currents after harmonics suppression via the TPF (a) and the ITM (b) methods

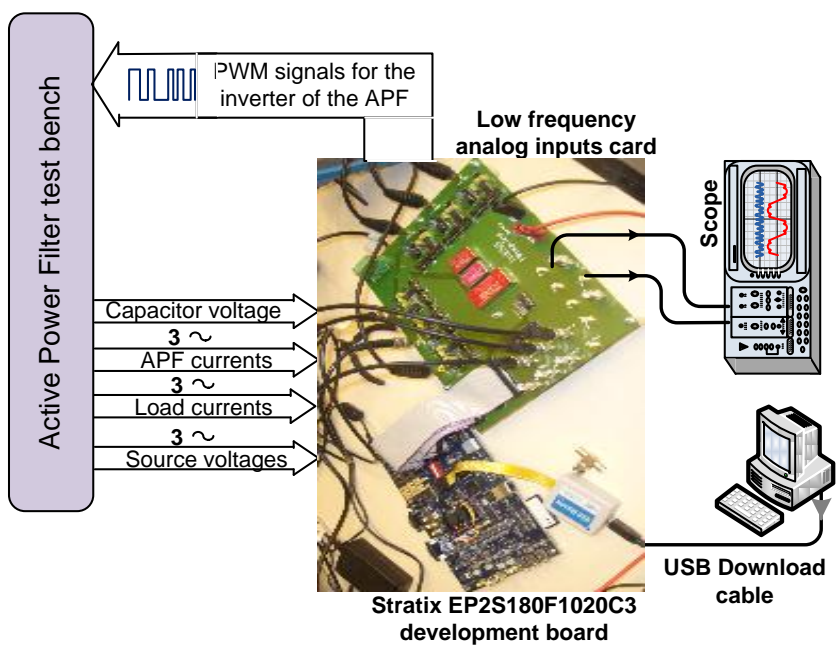

Fig 10. Principle of the experimental test bench

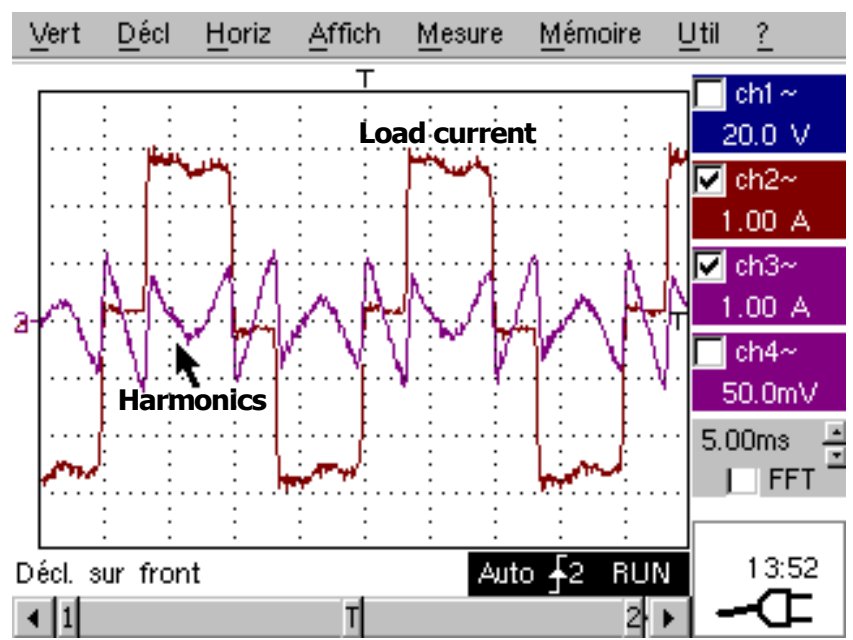

Fig 11. Experimental results - Harmonics extracted from the load current

Table I. Results from the harmonics detection methods

\begin{tabular}{lcc}
\hline \hline $\begin{array}{l}\text { Harmonic } \\
\text { detection method }\end{array}$ & $\begin{array}{c}\text { Settling } \\
\text { time }\end{array}$ & $\begin{array}{c}\text { Load current } \\
\text { fundamental component } \\
\text { THD after harmonics } \\
\text { separation }\end{array}$ \\
\hline$p-q$ & $27 \mathrm{~ms}$ & $0.5 \%$ \\
Direct & $50 \mathrm{~ms}$ & $0.95 \%$ \\
Three-monophase & $40 \mathrm{~ms}$ & $0.9 \%$ \\
$I T M$ & $45 \mathrm{~ms}$ & $1 \%$ \\
$T P F$ & $20 \mathrm{~ms}$ & $0.6 \%$ \\
\hline
\end{tabular}


Table II. Comparison of the different compensation techniques

\begin{tabular}{|c|c|c|c|c|c|}
\hline Filtering method & $\begin{array}{c}\text { Need of current and/or } \\
\text { space transforms }\end{array}$ & $\begin{array}{l}\text { Adequate for } \\
\text { single phase }\end{array}$ & $\begin{array}{l}\text { Adequate for } \\
\text { three phase }\end{array}$ & $\begin{array}{c}\text { Number of } \\
\text { Adalines }\end{array}$ & $\begin{array}{l}\text { Source current THD } \\
\text { after compensation }\end{array}$ \\
\hline $\mathrm{p}-\mathrm{q}$ & yes & no & yes & 1 & $1.7 \%$ \\
\hline Direct & no & yes & yes & 3 & $1.9 \%$ \\
\hline Three-monophase & no & yes & yes & 6 & $1.8 \%$ \\
\hline ITM & no & yes & yes & 3 & $1.75 \%$ \\
\hline$T P F$ & yes & no & yes & 1 & $1.78 \%$ \\
\hline
\end{tabular}

Table III. Comparison of the hardware resources used on FPGA for the three methods

\begin{tabular}{|c|c|c|c|c|c|}
\hline \multirow{2}{*}{ Resources } & \multirow[b]{2}{*}{$p-q$} & \multirow[b]{2}{*}{ Direct } & \multicolumn{3}{|c|}{ Ratio in \% } \\
\hline & & & Tri-monophase & ITM & $T P F$ \\
\hline Total ALUT & 37 & 6 & 92.8 & 32 & 4 \\
\hline Total registers & 2,25 & 1.47 & 4.74 & 2.58 & 0.6 \\
\hline Stratix pins & 11 & 11 & 11 & 11 & 11 \\
\hline Memory bits (RAM) & 0 & 0 & 24 & 24 & 4 \\
\hline 9-bit DSP & 99 & 88 & 100 & 100 & 57 \\
\hline \multirow[t]{2}{*}{ PLL } & 8 & 8 & 8 & 8 & 8 \\
\hline & \multicolumn{5}{|c|}{ FPGA average resources consumption in $\%$} \\
\hline \multirow{3}{*}{$\begin{array}{l}\text { For 3-phases } \\
\text { compensation }\end{array}$} & 26.2 & 19.08 & N/A & 29.6 & 14.1 \\
\hline & & & \multicolumn{3}{|c|}{$\begin{array}{c}\text { Calculation resources consumption } \\
(R A M+D S P+A L U T)\end{array}$} \\
\hline & 45.3 & 31.33 & N/A & 52 & 21.6 \\
\hline
\end{tabular}

Table IV. System parameters

\begin{tabular}{cc}
\hline \hline Power source & Values \\
\hline$V s, f$ & $40 \mathrm{~V}, 50 \mathrm{~Hz}$ \\
\hline \hline Active power filter & Values \\
\hline$V_{D C}, C_{D C}$ & $85 \mathrm{~V}, 4400 \mu \mathrm{F}$ \\
$R_{f} L_{f}$ & $5 \Omega, 5.8 \mathrm{mH}$ \\
$f_{s w}$ & $12.5 \mathrm{Khz}$ \\
\hline \hline Non linear load & Values \\
\hline$R_{L,} L_{L}$ & $20 \Omega, 15.4 \mathrm{mH}$ \\
\hline
\end{tabular}

Table V. THD of the grid current under sinusoidal voltage conditions after the connection of the APF

\begin{tabular}{lc}
\hline \hline $\begin{array}{l}\text { Harmonics } \\
\text { extraction method }\end{array}$ & $\begin{array}{l}\text { THD } \quad \text { after } \\
\text { compensation }\end{array}$ \\
\hline$p-q$ & $4.8 \%$ \\
Direct & $4.4 \%$ \\
$I T M$ & $4.2 \%$ \\
$T P F$ & $5.2 \%$ \\
\hline
\end{tabular}

